has its set of exercises-about 100 in total-in some of which a good reactor background knowledge is assumed. Most of the exercises require the derivation of a mathematical function or equation similar to that in the text. A few exercises are numerical but no answers are given; they are to be checked by comparison with values quoted in the text or in references.

The text excels in cross referencing both forward and backward. Fortunately this is done unobtrusively and does not distract the reader's attention. External references are extensive, ranging up to 100 references in several chapters and up to 1970 in date. These references taken in conjunction with the Science Citation Index should ensure a competent survey of the reactor literature well into the future.

The book is obviously destined as a reference work but its place is likely to be in libraries or on the shelves of reactor designers and academics. It is undoubtedly a sound investment for specialists.

R. R. OSBORNE

\section{Water Balance}

Endocrines and Osmoregulation: A Comparative Account of the Regulation of Water and Salt in Vertebrates. By P. J. Bentley. Pp. xvi +300 . (Springer: Berlin and New York, 1971.) 58 DM; $\$ 16.80$.

VERTEBRATES occupy a very wide range of ecological niches, ranging from sea and fresh water to arid deserts. For the most part, homoeostatic mechanisms are brought into play to limit variations in the constitution of the body, in which water and electrolyte composition is of great importance. Here there are two important areas, the relationship of the whole animal to the particular environment and the maintenance of the different compartments of the body, so that, as a simple example, a solution largely composed of sodium chloride bathes cells with high potassium content. Investigation of such problems requires concepts of physico-chemistry and biochemistry and for which the first fourteen pages of chapter 1 present a brief introduction. The biological structures which take part in exchanges of water and electrolytes, such as cell membranes, capillaries, skin, gills, gut, urinary bladder and kidneys, are then discussed. The first chapter thus gives the background to the main purpose of the book, that is to show how the endocrine system impinges on these basic facets of regulation throughout the vertebrates. Chapter 2, the vertebrate endocrine system, starts off with a page and a half on servo-control systems and, in smaller print, gives the criteria of endocrine function, the methods used and the difficulties encountered. This is a short but important section of the book and should either have been cast in the general format or added as an appendix. Each gland is then taken in turn and constitutes a summary of comparative endocrinology, with emphasis on mechanisms concerned with water and electrolyte movements. Although much has to be repeated in the follow. ing five chapters, it does provide an introduction to endocrine organs and gives the background for wider reading by younger workers to whom the book is primarily devoted.

The main contribution of the book lies in the survey of the vertebrate classes, starting with the mammals and ending with the fishes, both agnathous and gnathostomatous. These chapters are particularly well done and the coverage of the literature is excellent. It is especially pleasing to find the Australian fauna given their full due. Whilst some might rejoice in the great research application to sheep, a real consumer concept, the comparative endocrinologist also hopes for more investigation of the rich variety of animals peculiar to that continent. With the vertebrate endocrine glands, particularly posterior lobe and adrenocortical hormones, the author comes into his own. His authoritative survey, including discussions on the animal's physiology in relation to the environment, is well documented and supported by good tables and figures. I strongly recommend it as an essential reading and reference book for younger and older workers alike.

\section{Chester Jones}

\section{Medical Policy}

Medicine and Society: Contemporary Medical Problems in Historical Perspective. (Four Symposia.) Pp. viii +378 . (American Philosophical Society: Philadelphia, 1971.) $\$ 2.50$.

THE collection of any group of papers as a book always presents hazards, and this photo-offset typescript of four symposia conducted by the Departments of the History and Sociology of Science of Bryn Mawr College and the University of Pennsylvania is no exception. Organized under four headings, "Human Experimentation," "Drug Addiction and Control," "The Twentieth Century Hospital," and "Alternative Traditions of Medical Care," fourteen lectures and the discussions which followed have been published without benefit of editing. The virtue of informal presentation must have been compelling at the time of these meetings; unfortunately this does not lead to a coherent volume. A cross-disciplinary approach requires more rigorous control of material than these circumstances elicited, and the verbatim transcription of the discussions suggests the need for a more confining focus in the absence of a common methodological framework. Undoubtedly these symposia were enormously stimulating for all participants, but they do not make especially illuminating reading.

The formal participants included historians, sociologists, physicians from several specialized fields, a lawyer and a hospital administrator; men and women whose published works command respect and provide the resources we turn to for guidance in interpreting the data of past and present medical events. To name Renée Fox, Robert S. Morison, David F. Musto, Charles Rosenberg, Anne R. Somers, Jeanne Brand and Mark G. Field gives some indication of the breadth of scholarship encompassed. These symposia were not, however, the time for presenting new research, nor the occasion for rewarding syntheses. The panel on "Drug Addiction and Control" seemed the most successful exchange, for Dr Musto's contribution provided both data and analysis which induced comparative examination. The final session on "Alternative Traditions of Medical Care" seems, for quite different reasons -perhaps in part because the student participants became accustomed to the opportunities and constraints of this type of discussion-to have evoked the sharpest confrontations. Unfortunately this seems also to have resulted in more heat than light.

Historians of medicine will welcome this pioneering attempt to engage experts from diverse fields and students of several disciplines in an exchange of information and ideas. From this kind of interaction new and more fruitful methods of historical and contemporary analysis should eventually emerge. At the moment one must conclude, however sadly, that the papere published here resemble sturdy ocean-going vessels passing each other by on the high seas, and too often this encounter takes place in the dark.

Barbara G. Rosenkrantz

\section{Mosquitoes in General}

Mosquitoes. By J. D. Gillett. Pp. xiii + 274. (Weidenfeld and Nicolson: London, November 1971.) $£ 5.90$.

THE significance of mosquitoes as vectors of disease was demonstrated during the later years of the nineteenth century, and for the past seventy years mosquitoes have been subjected to intensive study. They comprise some 2,500 species in thirty-three genera, and many species have been implicated as vectors of human disease, transmitting viruses, protozoa or nematodes. Laboratory studies have been concentrated on 